\title{
KONSEP SATUAN HILANG ENERGI DALAM ALIRAN FLUIDA
}

\author{
Mubiar Purwasasmita \\ Program Studi Teknik Kimia, Fakultas Teknologi Industri \\ Institut Teknologi Bandung \\ Jalan Ganesha 10 Bandung, 40132 \\ Email: mubiar@che.itb.ac.id filiasi Penulis
}

\begin{abstract}
Abstrak
Analog terhadap konsep 'Bilangan Satuan Perpindahan' (NUT) yang dikemukaan oleh Chilton dan Colburn (1933), berikut ini dikemukakan definisi 'Bilangan Satuan Energi' (NUE) yang hilang/digunakan dalam sembarang alat yang mewadahi fluida yang bergerak secara mantap. Bahasan ini diangkat dari berbagai tulisan dan kuliah Prof. Le Goff di Ecole Nationale Superieure des Industries Chimique (ENSIC) - Nancy, Perancis. Bahasan diawali dengan mengemukakan dua cara 'hilangnya' energi mekanik, yakni secara gesekan ciskos dan secara inersia (oleh pelontaran atau penahanan paket fluida). Kemudian, 'Satuan Hilang Energi' ditunjukkan sebagai penjumlahan dua suku yang merupakan kedua cara penghilangan energi diatas dan suku ketiga yang merupakan ketidak-aditivannya. Ditunjukkan bahwa aditivitas kedua cara penghilangan energi tersebut dipenuhi dengan baik oleh aliran fluida dalam media porus (persamaan Ergun) dan agak baik oleh aliran seputar benda padat konteks yang tercelup (sedimentasi bebas). Aditivitas ini tidak lagi dipenuhi oleh aliran dalam pipa kosong, tetapi juga oleh aliran dalam bejana berpengaduk. Dalam makalah ini dibahas pula 'Bilangan Satuan Energi' yang hilang dalam berbagai konfigurasi geometris. Dalam setiap hal, besaran unik NUE dinyatakan sebagai fungsi dari berbagai bilangan tak-berdimensi yang telah biasa digunakan. Demikianlah pernyataan satuan fenomena hilang energi memungkinan untuk membandingkan densitas daya yang hilang dalam berbagai konfigurasi geometrik peralatan.
\end{abstract}

Kata Kunci: Bilangan satuan energi yang hilang, Bilangan Satuan Perpindahan, Persamaan Ergun, Aditivitas, konfigurasi geometrik

\section{Notasi Satuan Hilang Energi (Nue)}

Suatu benda (objek) bermasa $M$ yang diam dalam ruang kosong akan digerakkann sejauh $\mathrm{L}$ tertentu dalam suatu waktu tertentu. Bagaimanakah cara memindahkan objek tersebut agar jumlah energi yang digunakannya minimum?

Terdapat banyak lintasan yang mungkin (lihat Gambar-1a) agar kecepatan meningkat dan mencapai suatu maksimum pada saat tm. Salah satu diantaranya adalah percepatan progresif dari $0 \mathrm{~s} / \mathrm{d}$ tm sampai kecepatan mencapai harga maksimumnya, Vm, lalu perlambatan progresif antara waktu tm dan t.

Maka pertukaran energi antara objek dengan lingkungannya adalah $2 \times 1 / 2 \times \mathrm{M}$ vm2. Energi ini adalah harga minimum untuk $\mathrm{vm}=\mathrm{u}=\mathrm{L} / \mathrm{t}$, artinya untuk mekanisme yang disebut 'impulsi ganda' media luar memberikan suatu impulsi kepada objek yaitu energi $1 / 2 \mathrm{M}$ u2 dalam suatu waktu yang sangat singkat. Kemudian objek akan melanjutkan luncurannya pada kecepatan tetap (tanpa gesekan per-hipotesa). Pada saat akhir, objek melepaskan energi kinetiknya kepada media luar karena suatu impulsi baru dalam arah yang berlawanan. Karena perpindahan ganda enrgi ini adalah suatu proses irreversibel maka akan disertai hilangnya sejumlah tertentu energi potensial yang dikandung dalam lingkungan yang memungkinkan berlangsungnya perpindahan objek.

Bayangkan misalnya energi potensial dari lingkungan terjadi karena kompresi suatu bahan elastik (pegas). Penahanan sembarang pegas akan memberikan impuls awal pada objek. Sebaliknya, pengereman akhir dari objek akan dapat dilakukan pada kompresi pegas yang lain. Maka akan terdapat pemulihan energi potensial pada lingkungan, akan tetapi hanya sebagaian saja. Akibatnya, kedua gerakan kompresipengereman pegas ini akan menghasilkan pemanasan oleh karena gesekan intern dalam logam (Gambar 1-b).

Sebut Ed adalah jumlah energo mekanik yang hilang ke dalam panas. Maka evaluasi Ed dengan membandingkannya terhadap energi $M$ u2 yang diperlukan dengan lingkungan dapat ditunjukkan dengan persamaan:

$\mathrm{Ed}=\mathrm{NUE} \cdot \mathrm{M}$ u2

NUE adalah bilangan satuan energi yang hilang dalam operasi pemindahan tersebut, dan M u2 adalah satuan alamiah Energi yang dipindahkan: 
$\left[\begin{array}{c}\text { satuan energi } \\ \text { perpindahan }\end{array}\right]=M u^{2}=M\left(\frac{L}{t}\right)^{2}$

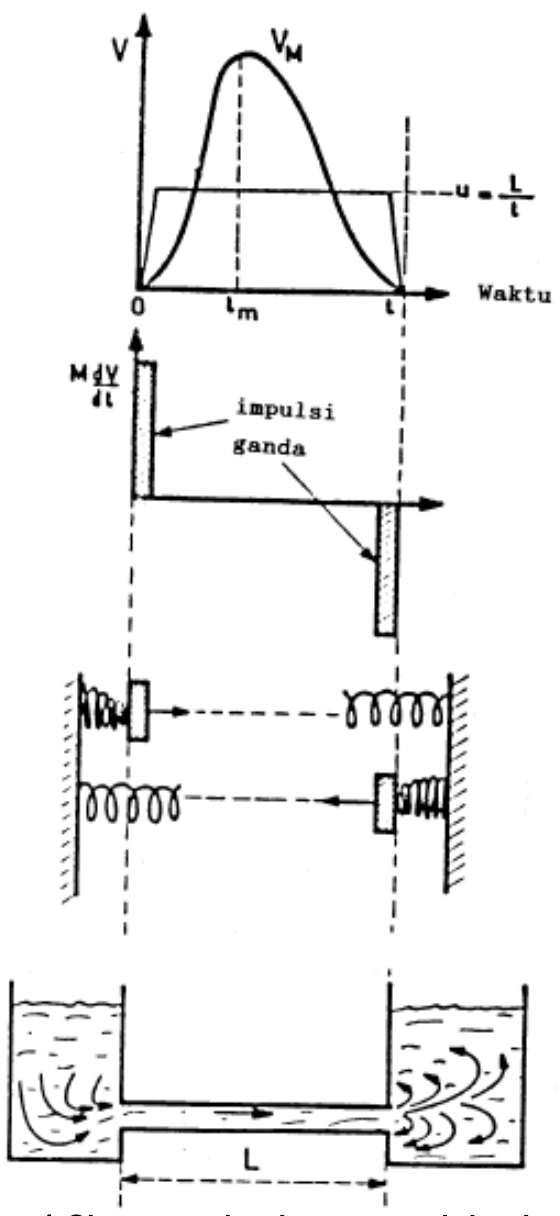

Gambar 1 Skema mekanisme energi dan impulsi

Persamaan NUE ini dikemukakan sebagai analogi terhadap notasi 'Bilangan Satuan Perpindahan' (massa atau panas) seperti telah dikemukakan oleh Colburn pada tahun 1933 [1]. Dapat ditunjukkan bahwa ketiga notasi ini adalah benar-benar serupa, bahkan harganya dapat sama, seperti dalam hal analogi Reynold.

Dalam hal pegas terbuat dari bahan yang sangat elastis, NUE dapat memiliki harga yang sangat kecil, biasanya pada orde 10-4. Sebaliknya, bila lingkungan berupa suatu fluida, NUE berada pada tingkat harga 100. Sebenarnya, dalam suatu fluida, Energi mekanik potensiap persatuan volume adalah tekanan motris $p^{\prime}=p+\rho g Z$, dan konversi Energi potensial ke dalam energi kinetic dalam fluida berlangsung dengan suatu rendemen yang jelek (seperti akan dibahas berikut ini). Energi hilang berada pada tingkat energi yang dipindahkan.

\section{Aplikasi Pada Suatu Fluida Yang Mengalir}

Konsep di atas akan diterapkan pada setiap unit volum fluida yang akan dialirkan dari satu wadah ke wadah yang lain melalui suatu pipa dengan panjang L (seperti pada gambar 1-c). Dapat diketahui bawa tekanan motris p' adalah Energi mekanik potensial per satuan volume. Maka dapat ditulis bahwa jumlah Energi hilang per satuan volume adalah

$p_{1}^{\prime}-p_{2}^{\prime}=N U E \cdot \rho \cdot u_{m}^{2}$

dimana:

$u_{m}$ adalah kecepatan rata-rata aliran dalam perpipaan : $u_{m}=\frac{L}{t}$

$\rho . u_{m}$ adalah satuan energi perpindahan dari satuan volume. NUE adalah Bilangan Satuan Energi hilang dalam seluruh perpipaan. Dapat dilihat bahwa NUE sama dengan bilangan tak berdimensi yang biasa disebut dengan bilangan Euler [2]: $N U E=E u$. Harga NUE dibentuk oleh tiga komponen, yaitu satu untuk setiap ujungujungnya dan satu untuk perpipaannya sendiri. Ketiga komponen ini akan dibahas pada Paragraf-4. Diketahui bahwa jumlah energi hilang dalam hadangan pada masukan dan keluaran perpipaan bergantung pada bentuk hadangan tersebut. Misalnya untuk pipa silinder kontraksi / ekspansi tiba-tiba pada suatu wadah yang besar, akan diperoleh:

Untuk keluaran : NUE $_{0}=0,50$

Untuk masukan : $\mathrm{NUE}_{\mathrm{i}}=0,25 \mathrm{~s} / \mathrm{d} 0,50$

Sehingga totalnya akan diperoleh:

$\mathrm{NUE}_{(\mathrm{i}-0)}=0,75 \frac{\mathrm{s}}{\mathrm{d}} 1$

Dalam singularitas pipa yang mencakup ekspansi karena adanya baffle, energi kinetic fluida yang terbentuk sepenuhnya hilang ke dalam energi pengadukan turbulensi paket-paket fluida, yang akhirnya kedalam energi pengadukan molekular (peningkatan temperatur).

Penting untuk dicatat bahwa dalam suatu bejana dengan pencampuran makro yang sempurna (seperti Gambar-2), energi kinetik beraturan dari pancaran sepenuhnya berubah ke dalam energi kinetic yang tidak beraturan untuk pengadukan paket-paket fluida. Akan tetapi, energi ini tidak selalu menjadi panas, karena tidak ada keharusan pencampuran mikro (hingga ukuran molekular) [3, 4]. 


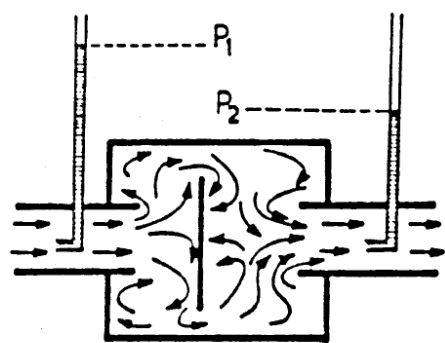

Gambar 2 Ilustrasi aliran turbulen dalam pipa yang terhalang baffle

\section{Dua Cara Hilang Energi: Secara Inersia Atau Secara Gesekan Viskos}

Ambil sekarang perpindahan objek pada kecepatan kostan rata-rata $u$, sepanjang jarak $L$ dan anggap ada gesekan antara objek dengan lingkungannya. Diketahui bawa akibat kedua cara penghilangan energi mekanik ini, yang merupakan dua fenomena ireversibel, membawah pada dua suku dalam persamaan yang menyatakan NUE. Untuk hal atau lingkungan objek yang berupa fluida Newton dapat dibahas sebagai berikut,

1. Suku inersia: bila objek ditahan beberapa kali sepanjang lintasannya, yang setiap kali memberinya satu satuan energi untuk mengentikan dan meluncurkannya kembali. Bila $A^{\prime}$ bilangan pemberhentian persatuan panjang lintasan, maka energi yang dipertukarkan adalah: L.A'.M. $u^{2}$.

Ini yang akan dikemukakan sebagai aliran turbulen suatu fluida: setiap objek akan berupa suatu paket fluida yang secara berulang kali dihentikan dan diluncurkan dalam turbulen.

2. Suku gesekan viskos: dikemukakan bahwa gaya gesekan dari objek terhadap fluida yang mengitarinya adalah sebanding dengan kecepatan $u$ dan ukuran karakteristik objek 'd' (hukum Stokes untuk fluida Newtonian), sehingga dapat ditulis:

$$
F f=(\text { tetapan }) \cdot \mu \cdot u d
$$

Kerja yang dilakukan oleh gaya ini atas lintasan $\mathrm{L}$ adalah b $\mu \mathrm{u} \mathrm{L}$ d. Dimana $\mathrm{b}$ adalah koefisien yang hanya bergantung pada bentuk objek $(b=3$ untuk objek seperti bola, dan untuk objek berbentuk sembarang $b=3 \psi$, dimana $\psi$ adalah koefisien kebolaan). Maka keaditivan kedua suku di atas energi hilang dapat ditulis:

$E_{d}=L A^{\prime} M u^{2}+b \mu u \mathrm{Ld}$
Sementara bilangan Reynolds relatif terhadap objek yaitu:

$$
\operatorname{Re}=\frac{\rho v d}{\mu}
$$

Dimana $\rho$ adalah rapat massa fluida.

Maka energi hilang dapat ditulis sebagai

$$
E_{d}=L M u^{2}\left(A^{\prime}+\frac{B}{R_{o}}\right)
$$

Dengan $B=\frac{18 \Psi}{\pi d} \cdot \frac{\rho}{\rho_{o}}$

B adalah tetapan karakteristik dari sistem dan $\frac{\rho}{\rho_{o}}$ adalah perbandingan rapat massa fluida dengan objek.

Dengan hal tersebut dapat diturunkan pernyataan Bilangan Satuan Energi yang hilang per satuan panjang sebagai:

$$
\frac{\mathrm{NUE}}{\mathrm{L}}=\mathrm{A}^{\prime}+\frac{\mathrm{B}}{\mathrm{Re}}
$$

Sebagaimana ditunjukkan diagram bilogaritma (Gambar-3) kita dapat membedakan 3 daerah yang dipisahkan oleh dua harga kritis bilangan Reynold sebagai berikut:

- Untuk $\mathrm{Re}>\mathrm{Re}_{2}$, suku pertama dalah sekurangkurangnya 10 kali lebih besar daripada suku kedua. Hal ini berarti lebih dari 90\% energi hilang karena kondisi inersia.

- Untuk RerRe 1 , suku kedua sekurangkurangnya 10 kali lebih besar dari suku yang pertama. Hal ini berarti bahwa lebih jauh dari 90\% energi hilang karena gesekan viskos.

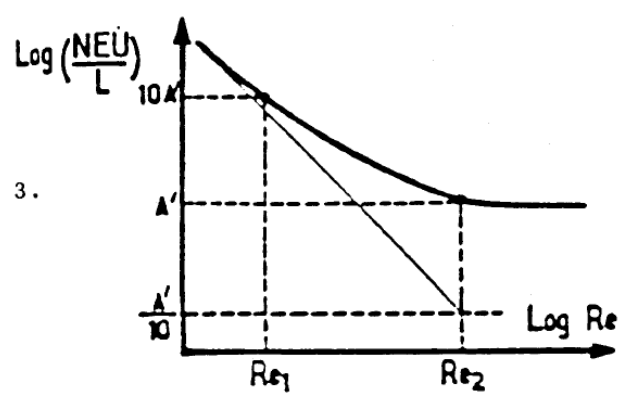

Gambar 3 Diagram bilogaritma

\section{Aliran Dalam Pipa Silinder Yang Panjang}

Ambil suatu pipa silinder berpenampang $\Omega$, yang di dalamnya mengalir suatu fluida dengan debot volum $\mathrm{V}^{\prime}=\Omega \mathrm{um}_{\mathrm{m}}$. Daya mekanik yang hilang 
karena gesekan pada dinding seluas A adalah: $E_{d}^{\prime}=V^{\prime}(P 1-P 2)$. Oleh karena $E_{d}^{\prime}=E d / A$ adalah densitas daya yang hilang pada dinding tersebut (dalam Watt/m²). Maka akan diperoleh:

$$
E_{d}^{\prime}=o_{d} \cdot A=\Omega \mathrm{u}_{\mathrm{m}}\left(P_{1}-P_{2}\right)
$$

Sementara itu, 'Bilangan Satuan Energi yang hilang' $P_{1}-P_{2}=N U E . \rho u_{m}^{2}$ sehingga akhirnya akan diperoleh

$$
\operatorname{NUE}=\frac{\mathrm{A}}{\Omega} \cdot \frac{\mathrm{f}}{2} \text { dengan } \frac{\mathrm{f}}{2}=\frac{\mathrm{e}_{\mathrm{d}}}{\rho \mathrm{u}_{\mathrm{m}}^{2}}
$$

Penting untuk dicatat bawa relasi ini adalah bersifat umum, sehingga dapat direapkan pada perpipaan yang secara makro bersifat silindris sekalipun dindingnya sangat kasar, atau bila pipa tersebut terbentuk oleh rongga-rongga dan penyempitan-penyempitan yang berurutan. Catatan ini akan sangat berguna untuk membahas aliran dalam media poros. Koefisien $f$ didefinisakan sebagai yang biasa ditemui dalam mekanika fluida sekalipun mungkin dikemukakan dengan cara yang berbeda.

Gambar- 4 menyatakan kembali beberapa kurva dari diagram klasik, dari moody [5] untuk pipa berpenampang bulat, sehingga $\frac{A}{\Omega}=\frac{4 L}{d} \quad$ yang artinya koefisien gesekan $f / 2$ merupakan fungsi bilangan Reynold untuk berbagai harga kekasaran realtif. e/d.

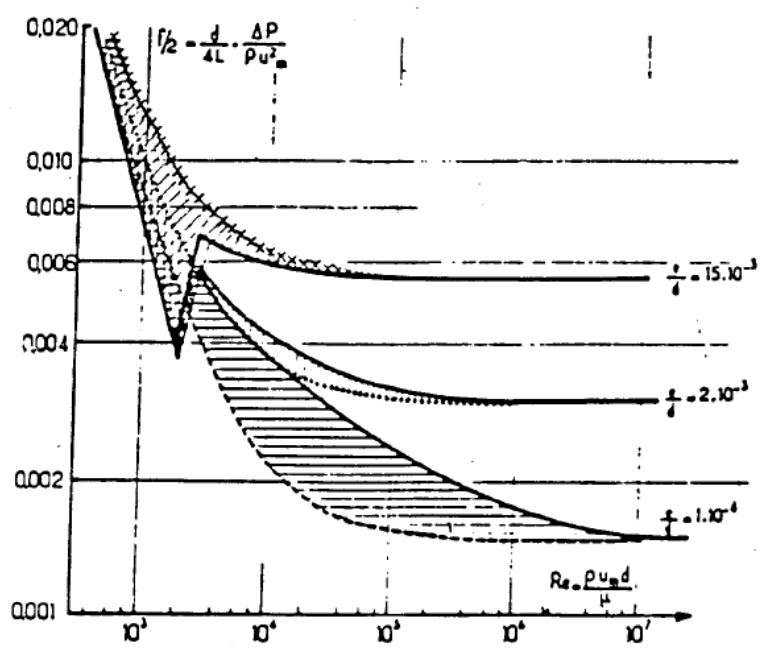

Gambar 4 Penyimpangan terhadap aditivitas cara penghilangan energi dalam pipa silinder panjang.

Ketiga kurva tersebut sepenuhnya ditarik dari hasil percobaan. Ketiga kurva ini secara teliti menyatakan relasi-8 dengan asimptot yang sama, yang berarti adanya aditivitas kedua cara hilangnya energi:

$$
\frac{\mathrm{f}}{2}=\frac{\mathrm{d}}{4}\left(\mathrm{~A}^{\prime}+\frac{\mathrm{B}}{\mathrm{Re}}\right)
$$

Dapat diamati bahwa untuk kekasaran relatif yang sangat tinggi $\left(e / d>5.10^{-3}\right)$ kurva percobaan sepenuhnya berada di bawah kurva yang bersangkutan dengan aditivitas: penyimpangan terhadap aditivitasnya selalu negatif. Sebaliknya, untuk harga kekasaran relatif lebih kecil, penyimpangannya, adalah negated dalam rejim laminar dan positif dalam rejim turbulen. Misalnya, untuk e/d $=1.10^{-4}$, penyimpangan relatif mencapai suatu harga maksimal pada orde 30\% untuk $\operatorname{Re} \sim 30.000$.

Adanya suatu non-aditivitas mem-punyai arti bahwa munculnya turbulensi dan gesekan viskos bukanlah fenomena yang saling tidak bergantungan. Bila kita naikkan kecepatan aliran secara progresif (yang berarti juga Re), system berubah dari rejim laminer ke rejim turbulen pada suatu selang harga Re yang sangat sempit. Terjadi pergantian yang cukup mendadak dari suatu cara penghilangan energy terhadap cara yang lainnya, dan tidak ada koeksistensi dari kedua cara ini dengan perubahan progresif dari yang satu terhadap yang lainnya. Hal ini berkebalikan terhadap apa yang akan terjadi dalam media porus.

Secara analog dengan notasi 'Tinggi Satuan Perpindahan' seperti dikemukakan oleh Chiolton dan Colburn [1] untuk fenomkena perpindahan massa dan panas pada dinding, sangat menarik untuk dikemukakan suatu notasi 'Tinggi Satuan energi' (atau lebih tepat lagi 'Panjang Satuan Energi') dengan menuliskan:

$$
\mathrm{L}=\text { NUE. HUE }
$$

Maka HUE secara definisi adalah panjang pipa dimana terjadi hilang satu satuan energi. Secara umum $H U E=\frac{\Omega \mathrm{Z}}{A f / 2}$ dan untuk pipa berdiameter $d:$

$$
\text { HUE }=\frac{d}{2 \mathrm{f}}
$$

Oleh karena itu, nilai HUE dapat kita nyatakan sebagai suatu perkalian terhadap diameter pipa. Diketahui bahwa apabila faktor gesekan berubah sedikit saja, antara $1 \times 10^{-2}$ dan $1 \times 10^{-3}$, bila harga Re berubah antara 1600 dan $2 \times 10^{8}$, dan untuk seluruh harga kekasaran dinding. Secara korelasi 'Tinggi Satuan Energi' pun berubah sedikit pula, selalu berad antara 25-250 diameter dalam selang Re yang sama, sebagaimana ditunjukkan dalam Gambar-5. Suatu harga rata-rata yang seragam dengan orde 50 s/d 100 diameter merupakan harga yang 
sangat bersesuaian dengan harga dalam praktek industri.

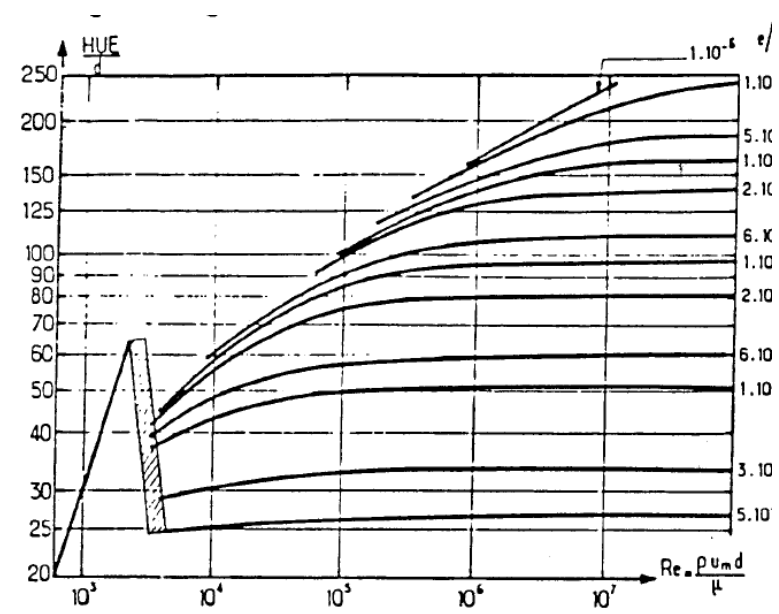

Gambar 5 "Tinggi Satuan Energi yang Dihilangkan" dalam pipa panjang, sebagai fungsi bilangan Reynold untuk berbagai harga kekasaran relatif dinding.

Catatan: perhitungan klasik hilang tekan total dalam suatu perpipaan yang panjang terdiri atas singularitas (seperti siku, TO, penyempitan, tampisan, dsb) yang sering kali dilakukan dengan menambahkan pada panjang pipa yang sebenarnya suatu panjang ekivalen untuk setiap singularitas itu. Maka prosedur ini akan memberikan pula penambahan pada 'Bilangan Satuan Energi'-nya.

\section{Aliran Dalam Media Poros}

Anggap sekarang bahwa fluida dengan debit volum total $v^{\prime}$ mengalir melalui suatu media poros. Ambil sebagai model dari volume poros ini suatu bundle dengan $N_{h}$ pipa silindir paralel berdiameter 'hidraulis' $d_{h}$ sedemikian sehingga penampang bebas untuk aliran adalah:

$$
\Omega=\mathrm{N}_{\mathrm{h}} \cdot \frac{\pi \mathrm{d}_{\mathrm{h}}^{2}}{4}
$$

Untuk memelihara sifat umum definisi yang telah dikemukakan terdahulu, sebut $U_{m}$ sebagai kecepatan rata-rata aliran dalam badan media poros, yakni:

$$
U_{m}=\frac{v^{\prime}}{\Omega}
$$

Sehingga dapat didefinisikan bilangan Reynold turbilen $\operatorname{Re}_{t}$ dan faktor gesekan yang bersangkutan sebagai:

$$
\operatorname{Re}_{\mathrm{t}}=\frac{\rho \mathrm{U}_{\mathrm{m}} \mathrm{d}_{\mathrm{h}}}{\mu} \operatorname{dan} \frac{\mathrm{f}}{2}=\frac{\Omega}{\mathrm{A}} \mathrm{NUE}=\frac{\mathrm{d}_{\mathrm{h}}}{4 \mathrm{~L}} \frac{\mathrm{P}_{1}-\mathrm{P}_{2}}{\rho \mathrm{U}_{\mathrm{m}}^{2}}
$$

Diketahui bahwa hasil percobaan tentang hilang tekan dalam media poros dinyatakan dengan cukup baik oleh rumus klasik dari Ergun [6] yang dapat ditulis dengan notasi yang sesuai sebagai berikut:

$$
\frac{\mathrm{f}}{2}=0,29+\frac{16,7}{\operatorname{Re}_{\mathrm{t}}}
$$

Sehingga dapat dikemukakan adanya aditivitas ke-dua cara penghilangan energi.

Oleh karena itu dapat kita turunkan pernyataan 'Panjang Satuan Energi' menurut Persamaan-10 sebagai berikut:

$$
\mathrm{HUE}=\frac{\mathrm{d}_{\mathrm{h}}}{1,16+66,7 \cdot \mathrm{Re}^{-1}}
$$

adalah sangat menarik untuk membandingkan harga HUE ini terhadap harga yang bersangkutan dengan aliran dalam pipa yang benar-benar silindris berdiameter 'hidraulis' $d_{h}$ yang setara, dan dengan kekasaran yang bervariasi.

Hal ini ditunjukkan dalam Gambar-6: Dalam batas-batas harga $R e_{t}$ yang diambil disini $(1 \mathrm{~s} / \mathrm{d}$ 5000) aliran dalam pipa silinder adalah laminar dan Panjang satuan Energi yang diturunkan dari hukum Poiseuille adalah $\frac{H U E}{d_{h}}=\frac{R e_{t}}{32}$ apapun kekasaran dinding pipa tersebut.

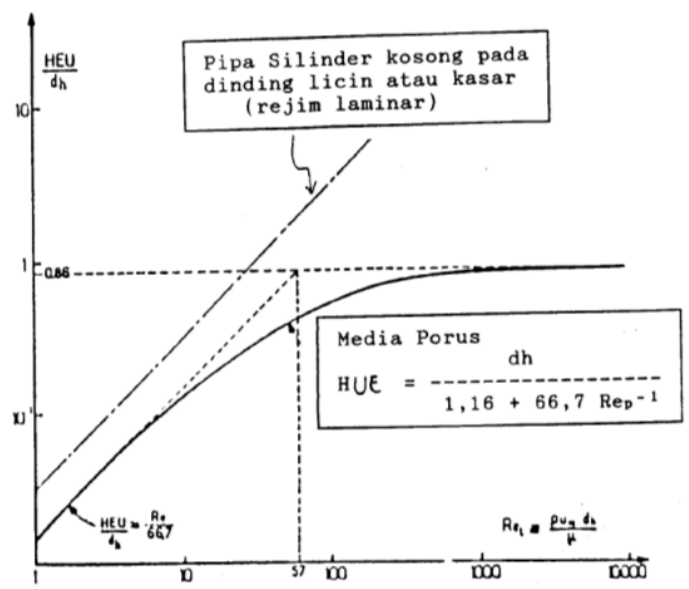

Gambar 6 Perbandingan nilai HUE terhadap harga yang bersangkutan dengan aliran dalam pipa silindris dan dengan kekasaran yang bervariasi.

Dapat dilihat dalam media poros bahwa Panjang Satuan Energi juga meningkat secara linier untuk harga Re yang kecil, pada setara dengan harga yang sangat keci untuk pipa silinder yang ekivalen. Kemudian secara asimptotis menuju suatu batas yang setingkat harga $d_{h}$.

$$
\frac{H U E}{d_{h}}=0.86 \text { untuk } R e_{t} \geq 1000
$$


Hal ini mempunyai arti bahwa pada kecepatan tinggi fluida ditahan dan diluncurkan lagi setiap kali ia melintasi suatu jarak yang mempunyai tingkat harga sama dengan diameter hidraulik $d_{h}$.

Untuk dapat melihat dengan lebih baik interpretasi fisik fenomena ini, ambil hal khusus dimana media poros dibentuk oleh unggun partikel bola berdiamter $d_{p}$. Dengan demikian, sangat mudah menyatakan diameter hidraulik sebagai fungsi dari $d_{p}$.

$$
\mathrm{d}_{\mathrm{h}}=\frac{2}{3} \frac{\varepsilon}{1-\varepsilon} \mathrm{d}_{\mathrm{p}}
$$

dimana Eadalah porositas unggun (fraksi volume kosong). Dengan hal tersebut dapat diturunkan pernyataan 'Bilangan Satuan Energi yang Hilang' sebagai berikut:

$$
\mathrm{NUE}=\frac{\mathrm{L}}{\mathrm{d}_{\mathrm{p}}} \frac{\varepsilon}{1-\varepsilon}\left(1,75+\frac{100}{\mathrm{Re}_{\mathrm{t}}}\right)
$$

Untuk penerapannya dalam angka, buat dalam relasi $L=d p$ dan $\varepsilon=0,50$ sehingga dapat dilihat bahwa pada saat fluida mengalir dengan kecepatan tinggi $\left(R e_{L} \gg 100\right)$, akar dalam suatu panjang $L$ sama dengan satu diameter partikel, dalam suatu media berporositas $\varepsilon=0,50$, akan terjadi penghilangan 1,75 satuan energi. Hal ini menunjukkan evaluasi berapa kali fluida dihentikan dalam turbulen yang terkandung dalam rongga-rongga, kemudian diluncurkan kembali dalam penyempitan yang menghubungkan rongga-rongga tersebut (lihat Gambar-7).

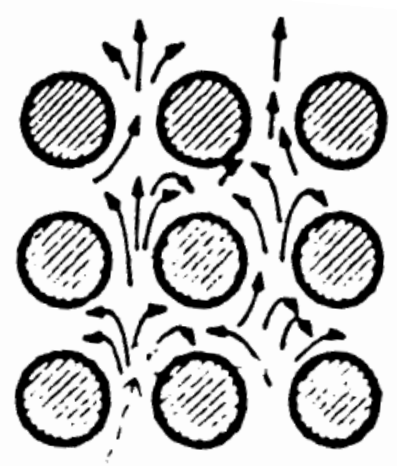

Gambar 7. Sebesar 1,75 satuan energi yang dihilangkan (dalam rongga-rongga) untuk $L=d p$ dan $L=0,5$.

\section{Aliran Seputar Benda Tercelup}

Ambil suatu benda tercelup simetri silindris yang ditempatkan dalam fluida yang mengalir secara mantap. Perhatikan satu benda tersebut dan bayangkan adanya suatu pipa aliran yang menumbuk penampang memotong benda tercelup tersebut (lihat Gambar-8).

Dari neraca energi mekanik dari satu satuan volume, antara dua titik yang terletak satu jauh di hulu dan satu lagi jauh di hilir benda tercelup tersebut, dapat dituliskan lagi disini Persamaan3, yaitu:

$$
P_{1}-P_{2}=N U E \cdot \rho u^{2}
$$

Dengan mengidentifikasi relasi ini pada definisi yang biasa digunakan yaitu koefisien seret $C x$, akan diperoleh:

$$
\mathrm{NUE}=\frac{\mathrm{Cx}}{2}
$$

Telah cukup banyak baasan teoritis dan eksperimental mengenai harga $C x$ ini sebagai fungsi dari bilangan Reynolds 'khusus', atau $R e_{p}=\frac{\rho U d_{p}}{\mu}$ (dimana dp adalah 'diameter' semu dari benda tercelup) dan berbagai faktor bentuk yang menyifatkan penyimpangan bentuk benda tercelup terhadap bola.

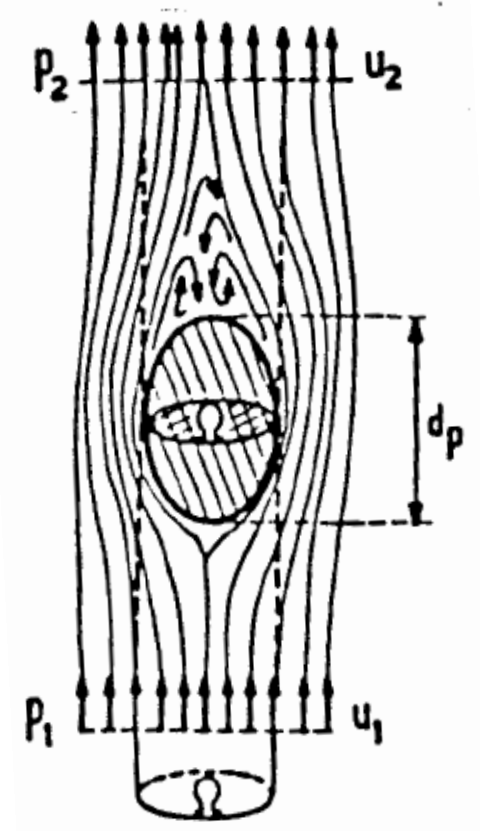

Gambar 8 Ilustrasi aliran yang menumbuk penampang sehingga memotong benda tercelup.

Dalam hal khusus dimana benda tercelup tersebut berupa bola (berupa butiran), hasil percobaan untuk Rep 300.000 dapat dinyatakan cukup baik oleh fungsi berikut: 


$$
\text { NUE }=0,21+12 \mathrm{Rep}^{-1}+\Delta(\mathrm{NUE})
$$

Suku pertama berkaitan dengan penghilangan energi oleh inersia dalam ulakan turbulen dari benda tercelup tersebut. Suku ini sangat menentukan untuk Rep $\geq 1000$ (rejim Newton). Suku ke-dua menyatakan gesekan viskos (rejim Stokes). Suku ke-tiga menyatakan non-aditivitas dari kedua suku diatas. Suku ini adalah suku koreksi yang hanya berarti dalam daerah antara, seperti ditunjukkan oleh kurva pada Gambar-9, atau juga dapat ditunjukkan dalam Tabel-1:

Tabel 1. Harga Suku Koreksi

\begin{tabular}{|c|c|c|}
\hline $\mathbf{R e}$ & $\mathbf{\Delta N U E}$ & $\boldsymbol{\Delta}$ (NUE)/NUE \\
\hline 0,1 & $-0,22$ & $-1,8 \%$ \\
\hline 0,5 & $+0,50$ & $+2,0 \%$ \\
\hline 1 & $+1,03$ & $+8,6 \%$ \\
\hline 10 & $+0,63$ & $+30 \%$ \\
\hline 50 & $+0,29$ & $+39 \%$ \\
\hline 100 & $+0,19$ & $+36 \%$ \\
\hline 1000 & $+0,004$ & $-0,8 \%$ \\
\hline
\end{tabular}

Suku koreksi tersebut mencapai nilai maksimum sebesar 39\% dari nilai total NUE untuk Rep $=50$. Sesuai dengan hasil percobaan Kaskas [7] yang dikemukakan oleh Molerus [8], dapat diberikan pada suku koreksi ini pernyataan berikut:

$\Delta \mathrm{NUE}=2 \cdot \mathrm{Re}^{-0,50}$

Kurva tersebut juga di-plot dalam Gambar-9.

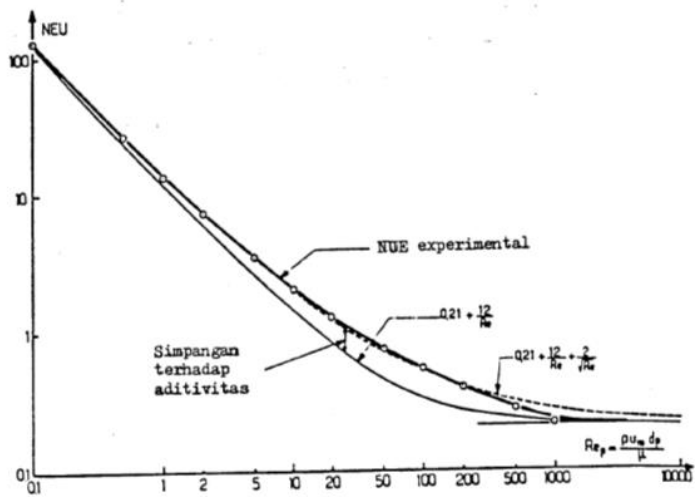

Gambar 9 Bilangan Satuan Energi yang Hilang dan aliran seputar benda berbentuk bola.

Menarik untuk dicatat bahwa juga pada kecepatan yang sangat tinggi (rejim Newton) hanya terjadi penghilangan 0,21 Satuan Energi di dalam ulakan turbulen dari suatu benda tercelup yang berupa bola. Diketahui pula bahwa koefisien seret mencapai harga numerik yang berbeda untuk benda-benda tercelup yang tidak berbentuk bola. Misalnya untuk suatu pelat tipis berdiameter $d$ yang tegak lurus aliran dapat diukur $C x=2$, yang memberikan NUE $=1$. Maka satu satuan energo dihilangkan dalam ulakan. Sebaliknya, dengan benda tercelup yang dibentuk dengan baik (streamline), suku inersia dapat lebih rendah dari 0,05. Akan diperoleh (dalam Paragraf-1) suatu interpretasi harga NUE $=0,21$ untuk suatu bola yang didasarkan atas model impulsi ganda seperti yang telah dikemukakan sebelumnya.

\section{BILANGAN SATUAN ENERGI YANG HILANG SEPUTAR BENDA TERCELUP DALAM REIM NEWTON}

Diketahui bahwa dalam rejim Newton, yakni untuk $500 \leq R e \leq 30.000$, koefisien seret $C x$ mempunyai suatu harga kuasi-konstan dengan tingkat harga $0,4 \mathrm{~s} / \mathrm{d} 44$ untuk suatu bola. Dari hal tersebut, dapat diturunkan Bilangan Satuan Energi yang hilang, yaitu pada tingkat $0,20 \mathrm{~s} / \mathrm{d}$ 0,22 .

Secara teoritis, harga ini dapat ditemukan kembali oleh suatu aplikasi sederhana model impulsi ganda, seperti yang telah dijelaskan pada Paragraf-1.

Ketika objek bergerak pada suatu jarak $L$ yang sama dengan panjangnya, ia akan mendorong satu volume $V$ fluida agar menyisih. Dalam suatu waktu $t=\frac{L}{u}$, setiap satuan volume fluida harus bergerak secara lateral dari suatu jarak $y$ sehingga dapat dengan mudah menghitung harga rata-ratanya, yaitu:

$$
\overline{\mathrm{y}}=\frac{2 \sqrt{2}-1}{6} d \approx 0,31 \mathrm{~d}
$$

Lalu ketika objek maju dari suatu panjang yang baru $L$, volume $V$ fluida akan bergerak lagi dalam arah kebalikannya, untuk kembali ke sumbu lintasannya. Energi minimal yang diberikan kepada fluida untuk melakukan pergerakan lateral gandanya, diberikan oleh prosedur tumbukan-ganda, seperti yang telah dijelaskan pada Paragraf-1: Fluida akan dianggap bergerak pada suatu kecepatan lateral konstan, yakni: $\frac{\bar{y}}{t}$.

Secara total, ketika volume $V$ fluida lewat dari posisi pertama ke posisi ke-tiga, seperti pada sketsa di Gambar-10, ia mempertukarkan dengan 'lingkungan luar' (fluida yang ada), yaitu energi mekanik:

$$
E_{L} \approx 2 V \rho\left(\frac{\bar{y}}{t}\right)^{z}
$$

Suatu perkalian $\alpha$ dari energi ini dihilangkan menjadi panas. Untuk setiap satuan volume fluida diperoleh: 


$$
E_{d}=0,19 \alpha \frac{d^{2}}{L^{2}} \rho u^{2}
$$

posisi ke-3

posisi ke-2

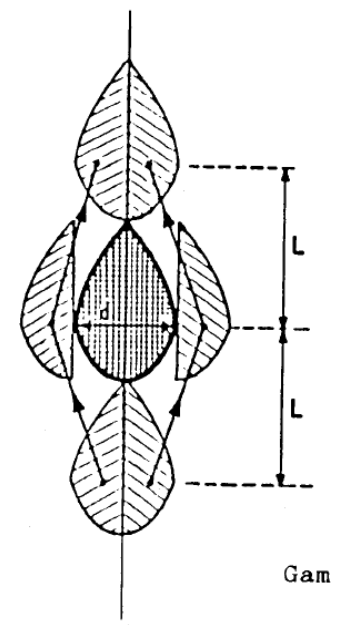

Gambar 10 Ilustrasi aliran fluida melalui berbagai posisi

Untuk suatu objek berbentuk bola $(d=L)$, akan diperoleh:

$$
N U E=\frac{E_{d}}{\rho u^{2}}=0,19 \alpha
$$

Dibandingkan dengan harga eksperimental NUE $=0,20 \mathrm{~s} / \mathrm{d} 0,22$, maka memberikan dengan baik $\alpha=1,1$.

\section{Membandingkan Butiran Tunggal Dengan Unggun Butiran}

Bandingkan hilang energi seputar partikel tunggal dalam ruang tak terbatas, dengan hilang energi seputar partikel yang sama pada media unggun yang mempunyai porositas $\varepsilon$. Jumlah partikel per-satuan volume dapat dinyatakan dengan: $n=\frac{6(1-\varepsilon)}{\pi d p^{3}}$.

Terlebih dahulu anggap bahwa keseluruhan $\mathrm{N}$ partikel berkelakuan sebagai suatu campura ideal (dalam arti termodinamika). Hal ini berarti bahwa energi yang hilang secara total, harus sebesar $N$ kali energi yang hilang seputar tiap partikel. Dengan menggunakan Persamaan-19 dan 20, dapat dihitung Bilangan Satuan Energi yang Hilang sepanjang L, yang dinyatakan dengan:

$$
\begin{aligned}
& (\mathrm{NUE})_{\text {ideal }}=\frac{\mathrm{L}}{\mathrm{d}_{\mathrm{p}}} \frac{3}{2}(1-\varepsilon)\left[0,21+12 \mathrm{Re}_{\mathrm{p}}^{-1}+\right. \\
& \left.\mathrm{Re}_{\mathrm{p}}^{0,50}\right]
\end{aligned}
$$

Kurva-kurva yang ditarik pada Gambar-11 memberikan (NUE) untuk lima harga parameter $\varepsilon$, yakni $\varepsilon=0,70 ; 0,60 ; 0,50 ; 0,40$; dan 0,33 untuk unggun berketinggian tertentu, yaitu $\mathrm{L}=$ $100 d_{p}$.

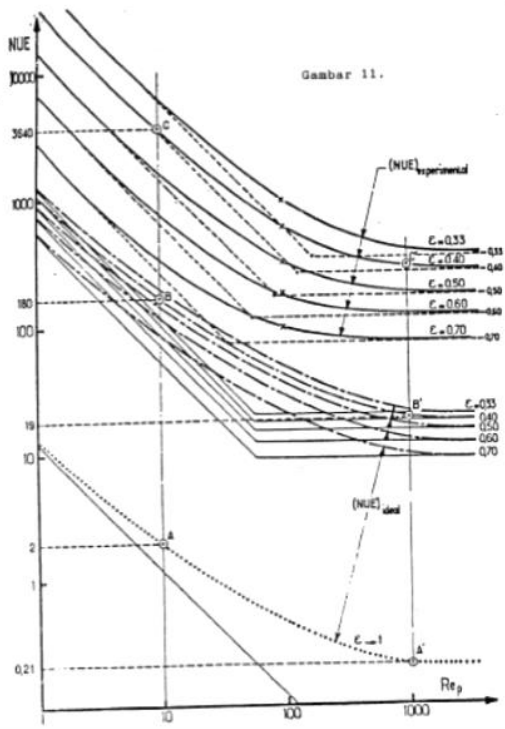

Gambar 11 Berlangsungnya degradasi tambahan energi disebabkan interaksi antara partikelpartikel (ketidak-idealan dari campuran partikel)

Pada Gambar-11 juga dikemukakan dengan garis titik-titik harga eksponensial NUE untuk harga $\varepsilon$ yang sama, yang dinyatakan oleh Persamaan Ergun (Persamaan-17). Setelah dinyatakan sebagai fungsi dari bilangan Reynolds khusus, $R_{p}$ yang diturunkan dari bilangan Reynolds turbular $R e_{t}$ oleh relasi:

$$
\operatorname{Re}_{\mathrm{p}}=\frac{3}{2} \frac{1-\varepsilon}{\varepsilon} \mathrm{Re}_{\mathrm{t}}
$$

Maka akan diperoleh:

$$
\mathrm{NUE}_{\text {nyata }}=\frac{\mathrm{L}}{\mathrm{d}_{\mathrm{p}}}\left[1,75\left(\frac{1-\varepsilon}{\varepsilon}\right)+150\left(\frac{1-\varepsilon}{\varepsilon}\right) \mathrm{Re}_{\mathrm{p}}^{-1}\right](24)
$$

Disini akan didapatkan suatu bentuk modifikasi yang sangat dikenal sebagai Persamaan Ergun [6].

Selisih $(N U E)_{\text {nyata }}$ - $(N U E)_{\text {ideal }}$ yang muncul pada Gambar-11 menyatakan suku ketidak-idealan. Ini adalah energi tambahan yang dihilangkan jarena partikel mengalami interaksi: setiap partikel berada dalam ulakan dari satu, bakan dari banyak partikel yang terletak di hulunya. Oleh karena itu, Gambar-11 juga menunjukkan berbagai sifat menarik dari suku ketidak-idealan ini. Bandingkan efek ini dengan koordinat ketiga titik $A, B$, dan $C$ yang bersangkutan dengan harga $R e_{p}$ yang sama. 
Misalnya, untuk suatu unggun berporositas $\varepsilon=$ 0,40 , dan ketebalannya sama dengan diameter partikel $\left(\Delta L=d_{p}\right)$ yang dipotong dari suatu unggun media poros, dapat dihitung:

- Untuk Rep $=10 \rightarrow$

$$
\begin{aligned}
& \circ \quad \mathrm{NUE}=1,80 \text { untuk campuran ideal } \\
& \circ \quad \mathrm{NUE}=36,40 \text { untuk campuran nyata }
\end{aligned}
$$

- Untuk $\operatorname{Rep}=1000 \rightarrow$

$$
\begin{array}{ll}
\circ & \mathrm{NUE}=0,19 \text { untuk campuran ideal } \\
\circ & \mathrm{NUE}=2,96 \text { untuk campuran nyata }
\end{array}
$$

Dapat dilihat bahwa suku ketidak-idealan adalah jauh lebih besar (15 s/d 20 kali lebih besar) dari pada suku yang ideal. Pengilangan energi terutama disebabkan oleh interaksi antara partikel dan ulakan dimana partikel tersebut berada.

Kesimpulan kedua adalah kedua kurva, ideal dan nyata, untuk harga $\varepsilon$ yang sama nampaknya dapat diturunkan satu dari yang lainnya, oleh suatu afinitas sederhana ordinat-ordinatnya. Dengan kata lain, interaksi antara partikel meningkatkan jumlah energi yang hilang, yang secara perkiraan berada dalam perbandingan yang sama, apapun harga $R e$ dalam selang 0,1 $\mathrm{s} / \mathrm{d}$ 1.000. Hal ini mempunyai arti bahwa, pengaruh interaksi atas suku viskos dan pengaruh atas suku inersia adalah proporsional, suatu hasil bahasan yang secara apriori tidak disangka-sangka.

\section{Bejana Berpengaduk Rotatif}

Ambil suatu bejana silinder yang di dalamnya berputar suatu pengaduk rotatif, yaitu suatu roda yang dilengkapi dengan pedal berdiameter $d$, lebar $b$, dan tinggi $h$. kecepatan sudut perputaranm pedal adalah $v=\pi N d$ dimana $N$ adalah jumlah perputaran per detik.

Ambil satu satuan volume fluida yang terseret oleh pedal dengan kecepatan $v$. peranalogi dengan (3) didefinisikan Satuan Energi Perpindahan dari Satuan Volume ini, yakni

$$
\rho v^{2}=\rho \pi^{2} N^{2} d^{2}
$$

Dalam hal lain, Em adalah daya menaknik yang diberikan atas roda rotatif dan diteruskan kedalam fluida yang terseret oleh pedal, lalu hilang dalam bejana. Gunakan hipotesa bahwa daya ini diteruskan pada cincicn fluida yang terseret oleh pedal dan volumenya adalah $v \approx$ $\pi d b h$ (lebar pedal $b$ dianggap cukup kecil bila dibandingkan terhadap diameter $d$ ). Akhirnya, Energi yang diberikan pada setiap satuan volume fluida dan setiap putaran adalah: $e_{m}=\frac{E m}{v N}$.
Sehingga, akhirnya Bilangan Satuan Energi yang hilang dalam bejana dapat dinyatakan sebagai:

$$
\mathrm{NUE}=\frac{\mathrm{e}_{\mathrm{m}}}{\rho \mathrm{v}^{2}}=\frac{\mathrm{E}_{\mathrm{m}}}{\rho \pi^{3} \mathrm{~N}^{3} \mathrm{~d}^{3} \mathrm{bh}}
$$

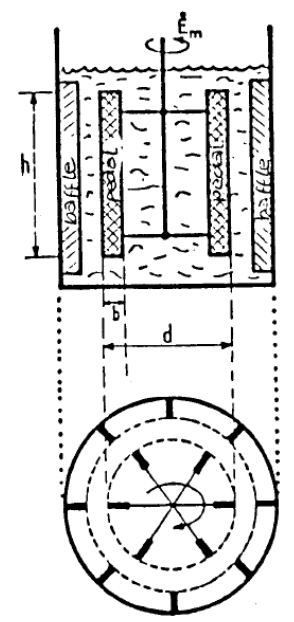

\section{Gambar 12 Sketsa bejana berpengaduk rotatif}

Di lain pihak, diketahui bahwa 'Bilangan Daya' $P_{0}$ adalah suatu bilangan yang tak berdimensi, yang biasanya didefinisikan sebagai:

$$
\mathrm{P}_{\mathrm{o}}=\operatorname{NUE} . \Psi_{\mathrm{p}} \text { dengan } \Psi_{\mathrm{p}}=\frac{\pi^{3} \mathrm{bh}}{\mathrm{d}^{2}}
$$

$\boldsymbol{\Psi}_{p}$ adalah faktor bentuk geometrik pedal, yang hanya bergantung pada ukuran pedal.

Terlihat bahwa Bilangan Daya adalah proporsional sederhana terhadap NUE. Adalah penting untuk dilihat dengan baik arti fisik dari besaran NUE ini, yaitu perbandingan energi yang hilang oleh tiap satuan volume fluida selama rotasi satu putaran penuh, terhadap energi kinetic rotasi dari paket satuan fluida yang sama:

$$
\text { NUE }=\frac{\left[\begin{array}{c}
\text { energi yg hilang } \\
\text { per satuan volume } \\
\text { dan perputaran }
\end{array}\right]}{\left[\begin{array}{c}
\text { energi kinetik rotasi } \\
\text { dari satuan volume }
\end{array}\right]}
$$

Dengan menggunakan relasi umum aditivitas (Persamaan-8), sementara dinyatakan bahwa NUE adalah jumlah dari dua suku:

$$
\mathrm{NUE}=\mathrm{A}^{\prime}+\frac{\mathrm{B}}{\mathrm{Re}_{\mathrm{t}}}
$$

Dimana $R e_{t}$ adalah bilangan Reynolds pengaduk yang didefinisikan oleh

$$
\begin{gathered}
\operatorname{Re}_{\mathrm{t}}=\frac{\rho \mathrm{Nd}^{2}}{\mu} \\
\mathrm{P}_{\mathrm{o}}=\mathrm{A}^{\prime \prime}+\frac{\mathrm{B} \prime}{\mathrm{Re}_{\mathrm{t}}} \\
\text { Dengan } A^{\prime \prime}=A^{\prime} \boldsymbol{\Psi}_{p} \text {, dan } B^{\prime}=B \boldsymbol{\Psi}_{p}
\end{gathered}
$$


Gambar-13 merupakan ringkasan dari Pustaka [9] dan [10] yang menunjukkan harga eksperimental Po sebagai fungsi $R e$ untuk roda yang dilengkapi oleh pedal berbagai ukuran dan bentuk (kurva dengan garis penuh).

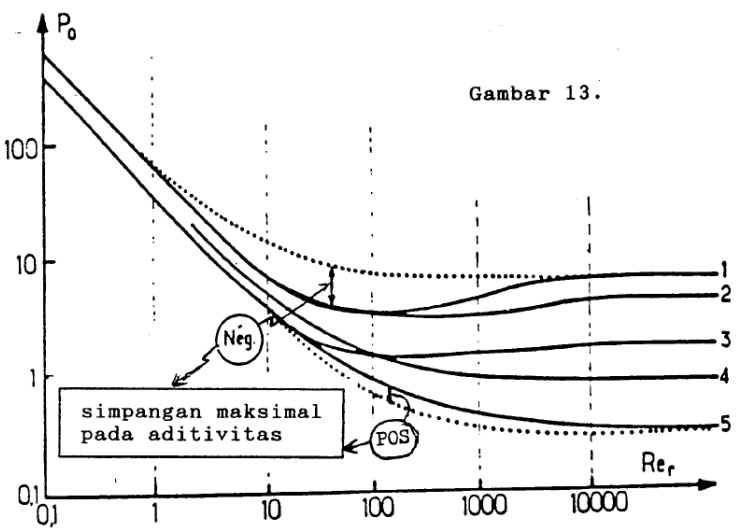

Gambar 13 Harga eksperimental Po sebagai fungsi $R e$ untuk roda yang dilengkapi oleh pedal berbagai ukuran dan bentuk

Dua kurva ekstrim yang juga diplot dalam gambar dengan garis titik-titik adalah kurva yang didasarkan atas asimtot yang sama, akan tetapi, dengan hukum aditivitas yang diberikan oleh Persamaan-28. Dapat dikemukakan bahwa untuk kurva yang rendah, aditivitas kira-kira dipenuhi dengan baik, naming dengan penyimpangan positif. Sebaliknya, untuk kurva yang lebih tinggi, Nampak pentingnya suatu penyimpangan negarif, yang ada pada tingkat $50 \%$ terhadap harga maksimumnya.

\section{Percobaan Interpretasi Koefisien A"}

Ingat arti koefisian A' dari Persamaan-28, yaitu A' adalah jumlah penahanan dan peluncuran kembail yang dialami setiap paket fluida per putaran roda. Beralasan untuk ditambahkan bahwa bilangan ini adalah proporsional terhadap jumlah $p$ pedal yang terdapat pada roda. Fungsi baffle pada dinding bejana adalah untuk menjaga agar tidak terjadi kontak dinding dengan cincin fluida yang kuasi-stasioner.

Setiap paket satuan fluida yang dibuat tidak bergerak oleh suatu baffle, mengalami suatu tumbukan setiap kali pedal dari roda melintas di depannya dan suatu fraksi dari paket ini terseret dalam pusaran fluida yang berputar. Kemudian, paket ini lewat lagi ke dalam cincin yang tidak bergerak dengan mengalami tumbukan kedua, dengan energi yang sama dan dalam arah yang berlawanan. Maka dapat dinyatakan:

$$
\mathrm{A}^{\prime \prime}=\mathrm{A}^{\prime} \Psi_{\mathrm{p}}=\alpha \pi^{3} \mathrm{p} \frac{\mathrm{bh}}{\mathrm{d}^{2}}
$$

Pernyataan A" ini adalah analog terhadap pernyataan yang telah dibuat oleh Le Lan dan Angelino [11]. Hal ini menarik untuk dikonfrontasikan dengan percobaan dalam suatu bahasan lebih lanjut. Namun, perlu dicatat dari sekarang bahwa untuk jenis roda standard [12], kita mempunyai $p=6 ; b=0,2$; dan $h=0,2 d$.

Dengan memasukkan harga-harga numerik ini kedalam Persamaan-32, akan diperoleh $A$ "' $=5 \alpha$. Agar harga ini cocok dengan harga eksperimental dari A" (yang berada antara 4 dan 6), maka harus diambil $\alpha \approx 1$.

Dengan kata lain, satu satuan energi dihilangkan pada setiap kali suatu paket satuan fluida dihantam oleh satu pedal dari pengaduk, yang dapat dibuktikan dengan model yang secara apriori telah dibayangkan.

\section{Kesimpulan Umum}

Dalam keempat jenis aliran fluida, telah didefinisikan Satuan Energi mekanik dari Satuan Volume fluida, yaitu 2, yang artinya dua kali energi kinetiknya. Telah dibahas energi yang hilang oleh fluida ini sepanjang pergerakannya atas jarak L, sehingga suatu perkalian dari satuan energi ini adalah 'Besaran Satuan Energi yang Hilang': NUE.

Konsep ini menunjukkan keunggulan berupa pembentukkan suatu keterkaitan umum pada keempat bilangan tidak berdimensi, yang masing-masing telah biasa digunakan dalam bidang tertentu mekanika fluida, yaitu:

1. Untuk aliran dalam pipa silindris panjang dan kosong, adalah faktor gesekan: $\frac{f}{2}=\frac{d}{4 L} N U E$.

2. Untuk aliran melalui suatu media poros, adalah juga faktor gesekan: $\frac{f}{2}=\frac{d}{4 L} N U E$.

3. Untuk aliran seputar benda tercelup yang berbentuk bola, adalah koefisien seret: $C x=2$ . NUE.

4. Untuk aliran berputar dalam suatu bejana yang dilengkapi oleh suatu pengaduk rotatif, adalah Bilangan Daya: $P_{o}=\frac{\pi^{3} b h}{d^{2}} N U E$.

Dapat dilihat bahwa bilangan tak berdimensi yang digunakan dalam setiap kasus diatas dinyatakan secara sederhana sebagai fungsi dari 'Bilangan Satuan Energi yang Hilang'. Koefisien pembandingnya adalah suatu faktor bentuk geometri, yaitu faktor yang hanya bergantung pada ukuran relatif dari dinding terhadap kontak dimana energi dihilangkan.

Pernyataan satuan fenomena ini memungkinkan kita memperbandingkan densitas daya yang dihilangkan, sekurang-kurangnya dalam ketifa 
hal pertama dan terutama untuk menyatakan secara kuantitatif pengaruh dari tekstur poros suatu unggun butiran atas energi yang hilang dalam tersebut.

Konsep Satuan Energi yang Hilang nampaknya dapat diterapkan pada masalah-masalah lain, seperti untuk mengevaluasi perilaku energetic alat pertukaran massa dan/atau panas.

Dalam Pustaka-13, sebenarnya konsep ini telah digunakan, tanpa setiap kali perlu dieksplisitkan secara jelas. Misalnya, untuk mengevaluasi performansi energetic operasi pencampuran: secara difusi, secara konveksi, turbulen, dan secara elongasi viskos.

\section{Daftar Pustaka}

[1] A.P. Colburn," A method of correlating forced convection heat transfer data and a comparison with fluid friction", Trans Am Inst Chem Eng, 29, 1933, pp.174-210.

[2] T.H. Chilton and A.P. Colburn, "Distillation and Absorption in Packed Columns A Convenient Design and Correlation Method." Industrial \& Engineering Chemistry 27.3 (1935): 255-260

[3] E. Plasari, R. David, and J. Villermaux, "Micromixing phenomena in continuous stirred reactors using a Michaelis-Menten reaction in the liquid phase." ACS Symp. Ser. Vol. 65. 1978.

[4] LeGoff, P., Rev. Gen. Therm. France, no 181, 1977, p. 15-28.

[5] L.F., Moody, "Friction Factor for Pipe Flow", Trans. Soc. Mech. Engrs, 66,1944, pp. 671

[6] S. Ergun, "Fluid flow through packed columns”,Chem. Eng. Progr, 48, 1952, pp.89

[7] S. Kaskas, Berechnung der stationären und instationären Bewegung von Kugeln in ruhenden und strömenden Medien, Diplomarbeit T.U. Berlin (1964)

[8] O. Molerus, Communication no A-2, 'Transfer proceses in particle systems.' “European Congres" Nurenberg, 28-30 march, 1977.

[9] A.S. Foust, L.A. Wenzel, C.W. Clump, L. Mans, and L.B. Andersen, "Principles of Unit Operations", J. Wiley, 1960.

[10] J.A.. Rushton, E. Costich, H.J. Everett," Power characteristics of mixing impellers. I", Chem. Eng. Prog, 46, 1950, pp. 395-467.

[11] Le Lan, A., Angelino, H., First European Conference on Mixing and Centrifugation Separation, Sept 1974, BHRA England (paper no A2).

[12] Nagata, S., “Mixing: principles and applications", Halsted Press, 1975.
[13] LeGoff, P., Second European Conference on Mixing, BHRA England (paper no D1), April 1977,

[14] LeGoff, P., Energetique Industrielle, tome 1, p. 191-210, Technique \& Documentation, Paris, 1979. 
Seminar Nasional Instrumentasi, Kontrol dan Otomasi (SNIKO) 2015

Bandung, Indonesia, 10-11 Desember 2015 